Birds of Eastern and North-Eastern Africa

By C. W. Mackworth-Praed and Captain C. H. B. Grant. Second edition. (African Handbook of Birds, Series 1, Vol. 1.) Pp. xxv $+806+53$ plates. (London and New York : Longmans, Green and Co., Ltd., 1957.) 45s. not.

FOR those who do not know the first edition of this excellent book the following information may be given : the area covered comprises Sudan, Eritrea, Abyssinia, Somalilands, Kenya Colony, Uganda, Ruanda-Urundi, Tanganyika Territory, part of Nyasaland and part of Portuguese East Africa. 618 species, from ostriches to pittas, are described, species or subspecies being discussed under the following headings : distinguishing characters, general distribution, range in East Africa, habits, nests and eggs, recorded breeding, food, call, and distribution of other races of the species (if any). In the second edition six species and three subspecies have been added as well as a considerable number of notes on distribution, habits, breeding, etc. The small marginal maps showing the geographical distribution of each species described deserve special mention, being not only an excellent idea but also a great and important visual help for the reader. There are fifty-three tables in colour depicting 1,027 species, painted by Roland Green, H. Grönvold, D. M. ReidHenry, Miss C. E. Talbot Kelly, and N. C. Lighton, and six tables of excellent photographs by Van Someren.

It is a pity that a bibliography has not been included in the book. A work of this kind (even in spite of the authors' intention) is considered by most readers as a reference book, and for this reason its value would be enhanced if it were to contsin refer. ences to the most important sources of information. A full bibliography of the East African birds is badly needed and the authors are certainly the ornithologists most competent to compile such a work, which might usefully form a third, supplementary volume to this book.

Elsevier's Dictionary of Electronics and Waveguides in Six Languages

English/American, French, Spanish, Italian, Dutch and German. Compiled and arranged on an English Alphabetical base by W. E. Clason. Pp. viii +628 . (Amsterdam : Elsevier Publishing Company; London: Cleaver-Hume Press, Ltd., 1957.) $90 s$.

7 HIS volume is one of an excellent series in which technical terms are defined in English, and then the corresponding words or phrases are given in five other languages. An ingenious arrangement of numbering the terms, which are in alphabetical order, makes it very easy by a simple cross-index to translate a term from any of the other languages. An earlier volume dealt with the terms used in the fields of television, radar and their associated antennæ (see Nature, 177, 1099 ; 1956) ; the present book covers the corresponding subjects of electronics and waveguides. More than 2,000 terms are defined and they include most of, if not all, the accepted words and phrases used in semiconductor and transistor work, as well as in the genersl field of electronics. Terms relating to physical electronics are not, however, included since it is intended to deal with the subjects of nuclear science and technology and radiation in a subsequent volume. It is noteworthy that the present dictionary includes definitions already established by the British Standards Institution, the
International Electrotechnical Commission and the publishers of the "Intermational Dictionary of Physics and Electronics". As with the former volume referred to above, the book is very well produced in $a_{0}$ handy size, with a flexible binding and a convenient thumb-index to the different languages. These qualities combined with the high technical standard throughout make this dictionary a reference work of permanent value to scientists and engineers engaged in the use of electronic devices and microwave equipment.

R. L. SMITH-Rose

\section{Lecture Notes on the Use of the Microscope}

By R. Barer. Second edition. Pp. vii +76. (Oxford : Blackwell Scientific Publications, 1956.) 7s. 6d. net.

URING the three years since its first appearance,

Dr. R. Barer's little book has become known to a wide circle of scientists ; it is evident from the demand for a second edition that this book meets a definite need, by introducing biologists to the correct use of one of their most important tools. As a result of the increasing use of the electron microscope in biology, it might be thought that the usefulness of the light microscope would diminish, but it is evident that the two methods should be used in conjunction, and that the proper use of the light microscope will continue to be of extreme importance. Dr. Barer has deliberately omitted any mention of the specialized forms of modern microscopy, because, as he points out in his preface, these methods are still in a state of flux but the fundamentals of direct microscopy do not change.

There have been only minor alterations in this edition, which resembles the earlier one in retaining its valuable chapters on the theory of the microscope and practical instructions for its use. The appendixes are of particular interest, giving simple experiments to illustrate such points as the effect of numerical aperture of both the condenser and the objective on resolution; the use of Köhler illumination is also described in detail. The book is very well written, and provides a clear explanation of the basic theory of the microscope; although it is intended for biology and medical students, all users of the microscope would be well advised to study it. If they did so, there would perhaps no longer be grounds for the author's opening comment that, "Probably no instrument is more often misused than the microscope"s.

S. Bradbury

\section{Old Stone Age}

By Stevan Celebonovic, with a Commentary by Geoffrey Grigson. (Nature and Art: a Series.) Pp. 96. (London: Phoenix House, Ltd., 1957.) 30s. net. $\triangle \mathrm{S}$ a picture book this volume is delightful and $A$ has a real value for the prehistorian. While many of the plates illustrate well-known palæolithic works of art, a number represent sculptures and drawings that are less known and not often reproduced. Frankly, the text is not very helpful, though some readers will find the chronological table at the end useful. Specialists will find little they did not know already, and non-specialists will not learn very much about the art or the cultures that produced it. But, of course, the illustrations are what really matter and at the price they are truly magnificent. No prehistorian should fail to have a copy by him, and the ordinary reader interested in art photography will revel in the beauty of some of the cave and home art subjects as here presented.

M. C. BuRkitT 